\title{
ECOLOGICAL COSTS AND BENEFITS OF DEFENSES IN NECTAR
}

\author{
LyNN S. AdLER ${ }^{1,2,5}$ AND REBECCA E. IRWIN ${ }^{3,4}$ \\ ${ }^{1}$ Department of Plant, Soil and Insect Sciences and Graduate Program in Organismic and Evolutionary Biology, \\ University of Massachusetts, Amherst, Massachusetts 01003 USA \\ ${ }^{2}$ Department of Biology, Virginia Tech, Blacksburg, Virginia 24061 USA \\ ${ }^{3}$ Institute of Ecology, University of Georgia, Athens, Georgia 30602 USA \\ ${ }^{4}$ Department of Biological Sciences, Dartmouth College, Hanover, New Hampshire 03755 USA
}

\begin{abstract}
The nectar of many plant species contains defensive compounds that have been hypothesized to benefit plants through a variety of mechanisms. However, the relationship between nectar defenses and plant fitness has not been established for any species. We experimentally manipulated gelsemine, the principal alkaloid of Carolina jessamine (Gelsemium sempervirens), in nectar to determine its effect on pollinator visitation, nectar robber visitation, and male and female plant reproduction. We found that nectar robbers and most pollinators probed fewer flowers and spent less time per flower on plants with high compared to low nectar alkaloids. High alkaloids decreased the donation of fluorescent dye, an analogue of pollen used to estimate male plant reproduction, to neighboring plants by one-third to one-half. However, nectar alkaloids did not affect female plant reproduction, measured as pollen receipt, fruit set, seed set, and seed mass. The weak effects of nectar alkaloids on female reproduction could represent a balance between the altered behavior of nectar robbers and pollinators, or it could be that neither of these interactions affected plant reproduction. Taken together, these results suggest that secondary compounds in nectar may have more costs than benefits for plants.
\end{abstract}

Key words: alkaloids; Carolina jessamine; costs and benefits; female plant fitness; gelsemine; Gelsemium sempervirens; male plant fitness; nectar defense; nectar robbing; pollination; secondary compounds; toxic nectar.

\section{INTRODUCTION}

Most organisms interact simultaneously with multiple species, including both mutualists and antagonists, but the relative importance of these selective pressures in shaping the evolution of phenotypic traits is not well understood. For example, most outcrossing plants must attract pollinators while also escaping antagonists such as herbivores, and the evolution of some plant traits may be constrained by opposing selection from herbivores and pollinators (Simms and Bucher 1996, Strauss and Lehtila 1997, Strauss et al. 1999, Adler and Bronstein 2004). Plants also may be under selection to encourage pollinators while discouraging animals that utilize nectar without transferring pollen, such as nectar thieves, nectar robbers, or microbes (e.g., Galen and Cuba 2001). Because these potential antagonists use the same resource as pollinators (i.e., nectar), effective defense mechanisms against these floral visitors may also deter pollinators.

Plant compounds associated with herbivore resistance are surprisingly common in floral nectar. Nectar that is poisonous or that contains secondary compounds

Manuscript received 24 January 2005; revised 15 April 2005; accepted 18 April 2005. Corresponding Editor: A. R. Zangerl.

${ }^{5}$ Present address: Division of Entomology, 204C Fernald Hall, 270 Stockbridge Rd., University of Massachusetts, Amherst, Massachusetts 01003 USA.

E-mail: 1sadler@ent.umass.edu has been reported in at least 21 different plant families (Adler 2000). In a broad survey, Baker (1977) found that nonprotein amino acids were found in 36 of 66 surveyed species (55\%), phenolics in 191 of 528 species (36\%), and alkaloids in 50 of 567 species (9\%). The widespread existence of nectar with secondary compounds is puzzling, given that the most widely recognized function of nectar is to attract pollinators. Several hypotheses regarding the benefits of defenses in nectar have been proposed (reviewed in Adler 2000), including deterrence of inefficient pollinators or nectar robbers, altered pollinator behavior to increase pollen transfer efficiency, and reduced microbial degradation. Despite the abundance of hypotheses assuming that nectar defenses benefit plants, no study has tested the plant fitness consequences of these traits. The goal of the present study was to test the ecological costs and benefits of this ubiquitous, but poorly understood, floral trait within the context of plant reproduction and floral visitor behavior.

Although most hypotheses assume that secondary compounds in nectar increase plant fitness, it is also possible that such compounds have no effect or are even costly. A lack of effect could occur if floral interactions have little consequence on plant reproduction. For example, if nectar robbing or thievery is not costly and if pollen transfer does not limit seed set, there may be little selection for or against secondary 
compounds in nectar. Alternatively, the possible costs of secondary compounds in nectar, including physiological costs of production and ecological costs such as pollinator deterrence, may outweigh benefits. Possible benefits of nectar compounds include deterring nectar robbers, thieves, and microbes, reducing geitonogamy (transfer of self-pollen between flowers on the same plant), or increasing outcrossing distance. It is important to note that secondary compounds in nectar may have arisen not in response to selection via floral interactions, but rather as a pleiotropic consequence of selection by herbivores for increased plant defense overall (as in Ehrlen and Eriksson 1993). Nonetheless, the evolutionary ecology of secondary compounds in nectar depends on the relationship between the trait and fitness, which has not been quantified for any system.

We experimentally tested the significance of secondary compounds in nectar within the context of floral visitor behavior and male and female plant reproductive success in Carolina jessamine (Gelsemium sempervirens; hereafter Gelsemium). Gelsemium produces the alkaloid gelsemine in leaves, corollas, and nectar. Moreover, Gelsemium is self-incompatible, is visited by an array of bees that vary in their pollen transfer efficiency, and is nectar-robbed by a carpenter bee. Thus, nectar traits that alter the quantity and quality of floral visits may translate into changes in male and female plant reproduction.

We used two approaches to experimentally test the plant fitness consequences of secondary compounds in Gelsemium nectar. First, we used an exploratory manipulation (Power et al. 1998) of nectar alkaloids in concentrations beyond the natural range to ask whether secondary compounds in nectar could affect floral visitor behavior and plant fitness. We used concentrations of secondary compounds that were artificially high vs. those that were low to assess whether there was any relationship between nectar alkaloids and plant fitness. This design is akin to nutrient enrichment experiments in which a treatment is applied in excess to ask whether systems can respond to a treatment manipulation relative to a control (e.g., Chapin et al. 1986). Finding that artificially high concentrations of alkaloids deterred floral visitors and decreased an estimate of male plant reproduction, we then reduced our alkaloid manipulation to a naturally occurring range of concentrations to assess the ecological consequences of nectar secondary compounds to floral visitor behavior and plant reproduction. We also determined whether nectar alkaloids had direct effects on plant reproduction by manipulating nectar alkaloids and hand-pollinating plants in the absence of floral visitors.

\section{Materials And Methods}

\section{Study system}

Gelsemium sempervirens (Loganiaceae) is a perennial vine native to the southeastern United States, oc- curring in disturbed forest edges and open pine forests (Ornduff 1970). Gelsemium blooms from early March into late April, producing up to several hundred yellow, tubular flowers per plant. Individual flowers have a standing crop of $1.08 \pm 0.10 \mu \mathrm{L}$ nectar (range $0-5.3$ $\mu \mathrm{L}$ nectar; all values are expressed as mean $\pm 1 \mathrm{SE}$ ), with a mean concentration of $47.7 \% \pm 1.2 \%$ sucrose equivalents (range $28-62 \%)(n=65$ plants; R. E. Irwin and L. S. Adler, unpublished manuscript). Flowers last 3-5 days. Fruits are dehiscent capsules that mature in September-October.

Gelsemium is self-incompatible and distylous; each plant has either long styles and short anthers ("pin" plants) or short styles and long anthers ("thrum" plants). Plants of each morph are incompatible with others of the same morph (Ornduff 1970). Anthers and stigmas appear to ripen simultaneously within a flower. Pollen grains from the two morphs overlap in size, so that the morph of individual pollen grains cannot be identified (Ornduff 1979).

The most common floral visitors of Gelsemium at our study sites were Bombus bimaculatus (bumble bees, Apidae), Apis mellifera (honey bees, Apidae), Osmia lignaria (blue orchard bees, Megachilidae), $\mathrm{Ha}$ bropoda laboriosa (blueberry bees, Anthophoridae), and the nectar robber Xylocopa virginica (carpenter bees, Xylocopidae), which make slits near the corolla base and insert their proboscis to rob nectar. We will use the genus name hereafter to refer exclusively to each species. Bombus, Osmia, and Habropoda transfer significantly more pollen per visit than Apis, which transfers more than Xylocopa (L. S. Adler and R. E. Irwin, unpublished manuscript).

Gelsemium leaves and corollas contain alkaloids that are highly toxic to mammals (Kingsbury 1964). Gelsemium nectar can cause bee poisoning (Eckert 1946, Hardin and Arena 1969), and young worker honey bees of an Italian strain develop abnormally when feeding on Gelsemium nectar (Burnside and Vansell 1936). We analyzed nectar samples pooled within six populations in 2002 and 19 populations in 2003 collected in Athens, Georgia, USA. Each sample consisted of $202 \pm 15 \mu \mathrm{L}$ of nectar (range 45-300 $\mu \mathrm{L}$ ) pooled from hundreds of flowers and analyzed using HPLC-MS (methods in Appendix A). We found mean gelsemine concentrations of $13.8 \pm 4.8 \mathrm{ng} / \mu \mathrm{L}$ (range $5.8-34.1 \mathrm{ng} / \mu \mathrm{L} ; n=6$ ) in 2002 and $35.0 \pm 13.1 \mathrm{ng} / \mu \mathrm{L}$ (range $6.6-246.1 \mathrm{ng} / \mu \mathrm{L}$; $n=19$ ) in 2003 .

\section{Experimental array and nectar manipulation}

We determined the effect of nectar gelsemine on pollinator and nectar robber behavior and components of male and female plant fitness using two different gelsemine concentrations in two years. All methods were identical for each year except where noted.

On 12 March in 2002 and 17 March in 2004, we transplanted rooted cuttings of 80 Gelsemium (divided evenly between pin and thrum morphs) to our field 
sites, the University of Georgia (UGA) Botanical Gardens in 2002 and next to the UGA greenhouses in 2004 in Athens, Georgia, USA. These sites are $\sim 3.5 \mathrm{~km}$ apart and are both in mown fields adjacent to forest. Each plant was buried within a $3.8-\mathrm{L}$ pot in an $8 \times 10$ array, with $1 \mathrm{~m}$ between pots. Plants were watered to help establishment, and then watered only during dry periods. One application (8 g) of 15-30-15 NPK fertilizer ("Colorburst;" Pursell Industries, Sylacauga, Alabama, USA) was added after transplanting to ensure that plants flowered synchronously with naturally growing plants. Although the addition of fertilizer may have made female plant reproduction more pollen- than resource-limited, this concern is not consistent with our results that plant reproduction was largely unaffected by pollinator preference and pollen deposition (see $R e$ sults). After flowering ended (17 April in 2002 and 19 April in 2004), plants were dug up, transferred into 18.9-L pots, and moved to a screen house for fruit maturation. Five plants died of frost damage in 2004 (two pin-low alkaloid, two pin-high alkaloid, and one thrum-low alkaloid) and were omitted from all analyses.

At transplanting, each plant was assigned randomly to a nectar manipulation treatment of either artificial nectar supplemented with gelsemine ("high alkaloid"), or artificial nectar without gelsemine ("low alkaloid"). Equal numbers of pin and thrum morphs were assigned to each treatment. In 2002, high-alkaloid plants received $0.5 \%$ gelsemine hydrochloride ("gelsemine" hereafter; Indofine Chemical Company, Hillsborough, New Jersey, USA) in a $40 \%$ (mass/volume) sucrose solution. Low-alkaloid plants received the sucrose solution without alkaloids. In 2004, high-alkaloid plants received only $0.025 \%$ gelsemine, in accordance with the highest level found in a natural population (i.e., $250 \mathrm{ng} / \mu \mathrm{L})$. We did not remove naturally produced nectar from flowers because removal can damage flowers and ovaries. Thus, our treatments should be considered a supplementation (high-alkaloid treatment) or dilution (low-alkaloid treatment) of existing nectar gelsemine. Assuming a mean pre-manipulation standing nectar crop per flower of $1.08 \mu \mathrm{L}$ with $35.0 \mathrm{ng} / \mu \mathrm{L}$ of gelsemine, flowers directly after nectar addition would have, on average, $3.08 \mu \mathrm{L}$ of nectar with $12.27 \mathrm{ng} / \mu \mathrm{L}$ of gelsemine in the low-alkaloid treatment in both years of study. The high-alkaloid treatment would have $3259.03 \mathrm{ng} / \mu \mathrm{L}$ of gelsemine in 2002 and $174.6 \mathrm{ng} / \mu \mathrm{L}$ in 2004.

Nectar treatments were performed at the whole-plant level each morning (six days per week) for the entire period that the plants flowered. Every morning at 09: 00 hours we added $2 \mu \mathrm{L}$ of nectar to all open flowers using Eppendorf Repeater Plus pipetters (Brinkmann Instruments, Westbury, New York, USA). Pipet tips were narrow enough to allow nectar to be placed at the corolla base near nectaries, and tips were cleaned with ethanol between each flower to prevent accidental pol- len transfer. Manipulated nectar volumes and sugar concentrations were well within natural ranges in both years.

\section{Effects of nectar alkaloids on pollinator and nectar robber visitation}

We determined the effect of nectar alkaloids on pollinator and nectar robber visitation daily. Floral visitors were observed for up to four hours after the first visitor (typically 10:00-13:00). We observed the entire field plot simultaneously and followed each visitor from entering to departing the plot. We used hand-held tape recorders and noted the number of plant visits, the number of flowers probed per visit, the time spent per flower, the time of day of each visit, and the species identity of each visitor. We observed all of the pollinating bees foraging for both pollen and nectar, but only saw $X y$ locopa forage for nectar. Thus we might predict that nectar manipulations would affect Xylocopa more than the pollinating bees. In 2002, we conducted observations for a total of 76.5 person-hours on 13 days from 14 March through 15 April. Multiple simultaneous observers were used when insect activity was high. Due to hard frosts and cool weather in 2004, several plants dropped flowers early and pollinator visits were infrequent. We conducted observations for 16.25 personhours on eight days between 18 March and 8 April.

We recorded the number of flowers open on every plant each day to calculate the proportion of flowers visited by insects. Excluding days with zero flowers open at the beginning and end of the season, plants averaged $4.89 \pm 0.31$ open flowers in 2002 (maximum of 44 flowers for one day) and $3.15 \pm 0.17$ open flowers in 2004 (maximum of 16 flowers). Nectar treatment did not affect the number of open flowers per plant in either year (repeated measures, treatment and date by treatment interactions; $F<2.2, P>0.14$ for all).

We analyzed the effect of nectar treatment and floral morph on pollinator and nectar robber visits using twoway ANOVAs. We used separate MANOVAs to analyze the proportion of flowers probed and time spent per flower for each visitor species. Responses were logtransformed to improve normality. All statistical analyses were performed using SAS Version. 8 (SAS Institute 1999).

One caveat about our experimental nectar manipulations is that they altered both the amount of nectar available to floral visitors and the timing at which that nectar was initially available. For example, nectar addition increased initial standing crop, which could potentially exaggerate differences in time spent per flower if high-alkaloid nectar was unpalatable. However, we found that time per flower for all bee species in both years was normally distributed (Shapiro Wilk $W>$ $0.956, P>0.05$ for all) rather than bivariate, suggesting that bees did not respond to flowers with a simple accept/reject behavior, but rather with a range of responses. Moreover, nectar was manipulated once 
per day. If high-alkaloid nectar was unpalatable, bees might consume less of it and the effects on insect behavior would persist longer than effects of low-alkaloid nectar. We performed a separate analysis using insect visits as the unit of replication to determine if insect behavior changed differentially in response to treatments over time each day. We found no significant time by treatment interactions for any of our behavior measures. The proportion of flowers probed changed over the day (but in different directions) for Habropoda and Xylocopa in 2002, and for Osmia in both years. However, this effect was consistent across nectar treatments and should not bias our results. Thus, we did not incorporate time of day into our models, which used plant, rather than visit, as the unit of replication.

Secondary compounds in nectar may affect not only the number of visits, but also the behavior of nectar robbers and pollinators following visits to plants with high vs. low nectar alkaloid levels. For example, if floral visitors use area-restricted foraging strategies to move out of distasteful or low-quality reward patches (e.g., Heinrich 1983, Maloof 2001), then floral visitors may increase interplant flight distances in response to high-alkaloid nectar relative to low-alkaloid nectar. Additionally, if floral visitors find nectar alkaloids distasteful or toxic, they may be more likely to leave the area after visiting plants with high relative to low nectar alkaloids. Both responses could contribute to increased outcrossing distance for plants with high alkaloids in nectar, assuming that pollinator movement is linked to realized gene flow. To examine the effect of nectar treatment on these visitor behaviors, we calculated the distance that each floral visitor traveled within the array after visiting every plant, and the probability of leaving the array after a visit to a high-alkaloid compared to a low-alkaloid nectar plant. Distance was analyzed with separate two-way ANOVAs for each visitor species and was log-transformed to improve normality of residuals. We measured the effect of nectar alkaloids on the probability of insects leaving the array after each plant visit using a chi-square test (PROC FREQ, SAS Version 8).

\section{Effects of nectar alkaloids on male and female plant reproduction}

Male reproduction.-We estimated pollen donation, a component of male reproduction, in both years using powdered fluorescent dyes (JST-300, Radiant Color, Richmond, California, USA). Powdered fluorescent dyes as pollen analogues have been used widely in pollination biology to compare estimates of male reproductive success among treatments (e.g., Waser and Price 1982, Irwin and Brody 1999). In a separate study, we found that the number of dye particles was strongly correlated with the number of pollen grains per stigma in trials with emasculated flowers (L. S. Adler and R. E. Irwin, unpublished manuscript). We assigned the two nectar treatments to different colors of dye. We randomly chose half of the plants from each nectar treatment (divided evenly among floral morphs) as pollen donors, and applied dye with toothpicks to anthers in all open flowers. Dye was applied directly after nectar manipulations on one day. Undyed plants were used as recipients. Stigmas from half of the open flowers on each recipient plant were collected 24 hours after dye application using clean forceps and were placed into individually marked vials. Forceps were cleaned in ethanol after each stigma collection to avoid dye or pollen transfer. Dye particles were counted using a dissecting microscope (Nikon model SMZ800, Melville, New York, USA) to determine whether stigmas received differential numbers of dye particles from high-alkaloid compared to low-alkaloid donors (indicated by different dye colors). Because we dyed anthers of all open flowers on donor plants, we might expect to see more dye transferred from the treatment that had more open flowers that day. Therefore, we standardized dye receipt by dividing the number of dye particles on each stigma by the number of flowers dyed in each treatment.

We dyed flowers on 20 March in 2002 and repeated the design on 28 March, reversing the donor/recipient assignments, so that we collected stigmas from every plant. To control for effects of dye color on pollinator behavior (e.g., Dudash 1991), we repeated the experiment on 2 and 5 April in 2002, with the dye colors reversed for each treatment. In 2004, we dyed plants on 26 March and 1 April; we could not repeat the experiment due to early flower senescence.

Male reproduction was measured as the mean number of dye particles received per stigma per plant from the two nectar treatments. We tested the effect of nectar treatment on dye receipt in each year using the variation between plants as the error term to avoid inflation of the error degrees of freedom (because there are two response variables per plant, number of high-alkaloid and low-alkaloid dye particles). In 2002, because the experiment was repeated with dye colors reversed between treatments, data were analyzed with repeatedmeasures ANOVA. In 2004, when dye transfer was measured only once, we analyzed data with ANOVA using treatment as a fixed effect and plant as a random effect. Seven plants in 2002 and 14 plants in 2004 that received no dye were omitted. Data were $\log (x+1)$ transformed to meet assumptions of normality.

Female reproduction.-We measured female reproduction both as pollen receipt on stigmas and as fruit and seed production. Pollen receipt was scored on the same stigmas collected for dye donation (see Male reproduction), by mounting each stigma in fuchsin stain (Kearns and Inouye 1993) on a glass slide and counting conspecific pollen grains under a compound microscope (Nikon Eclipse E400, Melville, New York, USA). One concern about our methodology is that stigma collection could have reduced fruit production. However, because we collected stigmas on a proportional rather than absolute basis (from half the open flowers on the day of collection), the number of stigmas 
collected controlled for plant size. If stigma removal reduced fruit set, our collection method should have affected all plants proportionally the same. Additionally, almost two-thirds of flowers do not produce fruits when hand-pollinated in the greenhouse with sufficient light, water, and nutrients, so stigma loss may not directly translate to fruit loss. Thus, we did not adjust female reproduction measures for stigma removal.

We counted the number of fruits and seeds per fruit for each plant. In 2002, we measured individual seed mass per fruit on fully developed, dry fruits in October. In 2004, we collected developing fruits in May, when fruits were fully expanded but still green, and measured the proportion of seed set. Each fruit was opened using fine-point scissors, and numbers of mature (expanded) seeds and aborted seeds were counted under a dissecting microscope. We calculated the proportion of seed set as (mature seeds)/(mature + aborted seeds).

Female reproduction was measured as the amount of pollen received on stigmas, number of fruits, seeds per fruit, and either seed mass (2002) or proportion of seed set (2004). Pollen receipt was analyzed as described previously for dye donation, using a repeated-measures ANOVA in 2002 and simple ANOVA in 2004. Fruits, seeds per fruit, and seed mass or proportion of seed set were analyzed separately for each year using two-way ANOVAs with nectar treatment, floral morph, and their interaction as independent factors. We did not use MANOVA because some plants did not produce fruit and thus lacked seed data. Fruits and seeds were $\log (x$ +1 )-transformed and proportion of seed set was arcsine(square-root $(x)$ )-transformed to meet assumptions of normality. Seed mass was normally distributed without transformation.

\section{Direct effect of nectar alkaloids on female plant reproduction}

Nectar alkaloids could have direct effects on plants, such as damaging floral tissues, as well as indirect effects, such as deterring insect floral visitors. The experiments just described cannot clearly disentangle the direct vs. indirect effects of nectar alkaloids on plant reproduction. Thus, we also tested whether nectar alkaloids in flowers could have affected fruit or seed abortion directly, in the absence of changes in floral visitor behavior. We performed a greenhouse experiment with 24 pairs of approximately 2-year-old Gelsemium plants during February and March 2003. Plants were paired by floral morph, overall size, and number of buds, and were assigned randomly to low-alkaloid or high-alkaloid nectar treatments within pairs. We used low and high alkaloid levels that matched those in 2002, with levels above the natural range. We hypothesized that using the highest alkaloid treatment would provide the strongest test of whether nectar alkaloids could reduce female reproduction by damaging floral tissue. We added $2 \mu \mathrm{L}$ of artificial nectar to every open flower every other day. Open flowers were hand- pollinated every other day using a mixture of pollen from at least two donor plants from the alternate morph. Hand-pollinating all flowers allowed us to determine the direct effects of nectar alkaloids on plant female reproduction in the absence of pollinator choice.

We measured fruit abortion regularly, collected developed fruits during two weeks in late April, and dissected fruits as previously described. We calculated the proportion of fruit set as (developed fruits)/(developed + aborted fruits). One plant did not set any fruit, and this pair was not used in tests of seed set. We analyzed the direct effects of nectar alkaloids on the number of flowers produced, number of fruits produced, proportion fruit set, number of seeds per fruit, and the proportion of seed set with separate paired $t$ tests for each response variable.

\section{RESULTS}

\section{Effects of nectar alkaloids on pollinator and nectar robber visitation}

Insect visits were much more common in 2002 than in 2004. Flowers were visited at a mean rate of 0.19 probes per flower per hour in 2002, and 0.04 probes per flower per hour in 2004. In 2002, we observed a total of 3369 flower probes, of which nectar-robbing Xylocopa were by far the most frequent floral visitors (61.6\% of all probes), followed by Osmia (10.4\%), Habropoda (10.1\%), Apis (7.2\%), Bombus (6.0\%), and Lepidoptera (4.7\%). In 2004, we observed only 297 flower probes, probably due to cool temperatures and multiple hard frosts during the flowering season. $\mathrm{Ha}$ bropoda were the most common (34.3\% of all probes), followed by Xylocopa (30.6\%), Apis (13.8\%), Osmia (12.5\%), Lepidoptera (5.4\%), and Bombus (3.4\%). Bombus were excluded from further analyses in 2004, and Lepidoptera were excluded from both years, due to low visitation rates.

Total plant visits. - Nectar alkaloids did not strongly affect an insect's decision to begin foraging on a plant, regardless of whether we used nectar alkaloid levels that were artificially high (2002) or within the range of natural variation (2004). High nectar alkaloids reduced the total number of pollinator visits to individual plants by $22 \%$ in 2002 and by $14.5 \%$ in 2004 (mean \pm SE for high vs. low alkaloids; for $2002,8.9 \pm 1.0$ vs. $11.4 \pm 1.1$ visits; for $2004,1.71 \pm 0.25$ vs. 2.00 \pm 0.31 visits), but these effects were not significant (for 2002, $F_{1,75}=2.99 ; P=0.09$; for $2004, F_{1,71}=$ $0.46, P=0.50)$. Nectar alkaloids had no effect on nectar robber visits in either year $(F<0.5, P>0.5$ for both). Floral morph and the morph by treatment interaction had no effect on pollinator or robber visits in either year $(F<1.9, P>0.15$ for all).

Proportion of flowers probed and time per flower.Nectar treatment did affect visitor behavior after the initial decision to forage (proportion of flowers probed and time per flower). The nectar treatment significantly 

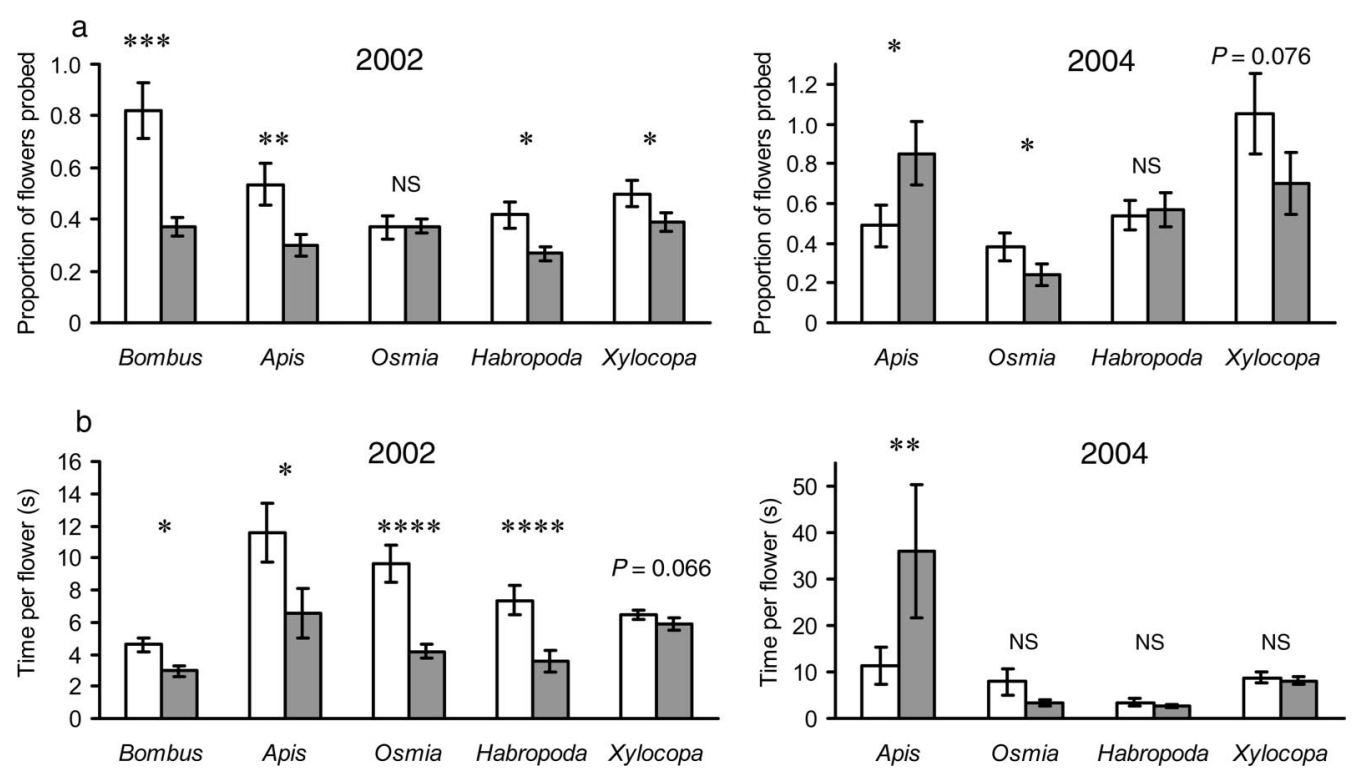

FIG. 1. Effect of nectar gelsemine on pollinator (Bombus bimaculatus, Apis mellifera, Osmia lignaria, and Habropoda laboriosa) and nectar robber (Xylocopa virginica) behavior when visiting Gelsemium sempervirens, measured as (a) the proportion of flowers probed per visit and (b) time spent per flower. Nectar treatments were a sucrose solution with $0.5 \%$ gelsemine in 2002 or $0.025 \%$ gelsemine in 2004 ("high," gray bars) and no additional gelsemine ("low," white bars). For Xylocopa, values in panel (a) refer to proportion of flowers robbed. Error bars represent 1 SE. Asterisks refer to level of statistical significance of univariate tests; "NS" indicates not significant.

affected behavior of all species in 2002, and of two out of three pollinator species in 2004 (Osmia and Apis but not Habropoda; Appendices B and C).

Univariate analyses revealed that, in 2002, artificially high nectar alkaloids reduced the proportion of flowers probed and time spent per flower by at least one-third for all pollinators except Osmia (Appendix B; Fig. 1). Floral morph altered the response of Osmia to nectar alkaloids. In pin flowers, Osmia probed a higher proportion of available flowers in the high-alkaloid than the low-alkaloid treatment (high-alkaloid $0.53 \pm 0.088$, low-alkaloid $0.32 \pm 0.068$; all values are expressed as mean $\pm 1 \mathrm{SE}$ ), but had the opposite response in thrum flowers (high-alkaloid $0.25 \pm 0.03$, low-alkaloid $0.42 \pm 0.057)$. High alkaloids reduced the proportion of flowers probed and time spent per flower by nectar-robbing Xylocopa, but only by $22 \%$ and $9 \%$, respectively (Fig. 1a, b). Xylocopa also spent nearly $20 \%$ less time on pin compared to thrum flowers, regardless of nectar treatment (pin $5.5 \pm 0.28 \mathrm{~s}$; thrum $\left.6.8 \pm 0.33 \mathrm{~s} ; F_{1,73}=8.79, P=0.004\right)$.

In 2004, when the high-alkaloid nectar treatment was within the natural range of nectar alkaloid levels, floral visitation was much lower due to cold weather, and the effect of nectar alkaloids on pollinator behavior was more variable (Appendix C; Fig. 1a, b). High-alkaloid nectar reduced the proportion of flowers probed by $O s$ mia, increased the proportion probed by Apis, and had no effect on Habropoda. High alkaloids increased the time per flower for Apis and had no effect on time per flower for the other pollinators. Habropoda spent more time on pin flowers with low-alkaloid nectar than any other treatment combination (for low alkaloid, pin 5.0 $\pm 1.7 \mathrm{~s}$, thrum $2.6 \pm 0.42 \mathrm{~s}$; for high alkaloid, pin 2.5 $\pm 0.28 \mathrm{~s}$, thrum $3.0 \pm 0.45 \mathrm{~s})$, but this effect was not significant in the MANOVA (Appendix C).

Nectar robbing was high but variable in 2004. High nectar alkaloids reduced the proportion of flowers

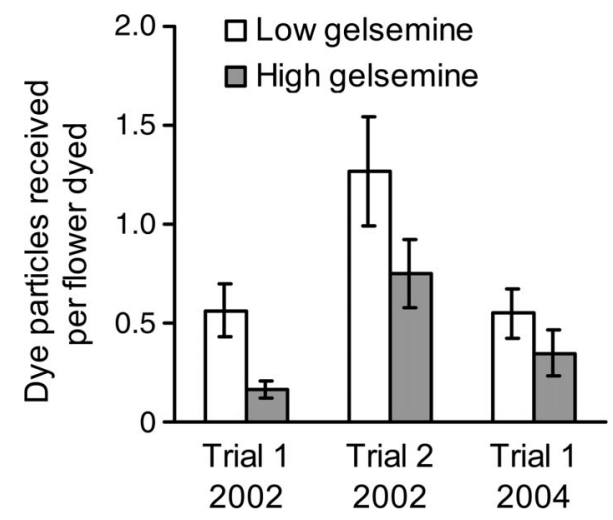

FIG. 2. Effect of nectar treatment on an estimate of male plant reproduction (dye receipt) in Gelsemium sempervirens during two separate trials in 2002 and one trial in 2004. Nectar treatments were a sucrose solution with $0.5 \%$ gelsemine in 2002 or $0.025 \%$ gelsemine in 2004 ("high," gray bars) and no additional gelsemine ("low," white bars). Dye receipt per stigma was standardized (by dividing the number of dye particles received by the number of flowers dyed during each trial). Error bars represent 1 SE. In 2002, Trial 1 occurred on 20 and 28 March; Trial 2 occurred on 2 and 5 April 2. In 2004, Trial 1 occurred on 26 March and 1 April. 
robbed by one-third (Fig. 1a), but this effect was not significant in the MANOVA and was only marginally significant in the univariate test (Appendix C). Nectar alkaloids had different effects on time per flower in the two floral morphs; Xylocopa spent more time on pin flowers with high-alkaloid compared to low-alkaloid nectar, but had the opposite response on thrum flowers (Appendix C; for pin, low-alkaloid nectar $6.32 \pm 0.78$ $\mathrm{s}$, high-alkaloid $8.68 \pm 0.74 \mathrm{~s}$; for thrum, low-alkaloid $11.00 \pm 1.82 \mathrm{~s}$, high-alkaloid $7.47 \pm 1.95 \mathrm{~s}$ ).

Floral visitor behavior after plant visits.-In 2002, when nectar alkaloids were artificially high, Bombus and Habropoda flew significantly farther after visiting a plant with high nectar alkaloids compared to low nectar alkaloids (for Bombus, low alkaloids $1.69 \pm 0.17$ $\mathrm{m}$ (mean $\pm \mathrm{SE}$ ), high alkaloids $2.98 \pm 0.40 \mathrm{~m}\left[F_{1,46}=\right.$ 10.87, $P=0.002]$; for Habropoda, low alkaloids 1.60 $\pm 0.13 \mathrm{~m}$, high alkaloids $2.06 \pm 0.17 \mathrm{~m}\left[F_{1,49}=4.65\right.$, $P=0.036])$. Nectar alkaloids did not affect the distance flown by other bee species ( $F<1.8, P>0.17$ for all). In 2004, nectar treatment did not affect the distance flown by all visitors combined or by individual species $(F<1.7, P>0.25$ for all). In both years, the probability of leaving the array was similar after visiting a plant with high compared to low nectar alkaloids. In 2002, 277 out of 798 visitors left after visiting highalkaloid plants, and 283 out of 868 left after visiting low-alkaloid plants; in 2004, 33 out of 83 left after visiting high-alkaloid plants, and 44 out of 101 left after visiting low-alkaloid plants $\left(\chi_{1}^{2}<1.3, P>0.3\right.$ for both). This pattern holds if data are analyzed separately per species $\left(\chi_{1}^{2}<2.65, P>0.1\right.$ for all).

\section{Effect of nectar alkaloids on male plant reproduction}

In 2002, when nectar alkaloids were artificially high, plants received three times more dye from plants with low-alkaloid nectar in the first trial, and almost twice as much dye in the second trial, compared to plants with high-alkaloid nectar (Appendix D; Fig. 2). In 2004, when nectar alkaloids were within the natural range, plants received almost twice as much dye from plants with low-alkaloid compared to high-alkaloid nectar, but this effect was only marginally significant (Fig. 2; $F_{1,26}=3.83, P=0.061$ ).

\section{Effect of nectar alkaloids on female plant reproduction}

In 2002, when nectar alkaloids were artificially high, nectar treatment did not affect any component of female reproduction. Pollen receipt varied among plants $\left(F_{58,130}=1.65, P=0.01\right)$, but was not affected by nectar treatment, date of the trial, or the date by treatment interaction $(F<1.5, P>0.2$ for all). Female reproduction, measured as number of fruits, seeds per fruit, and seed mass, was not affected by nectar treatment or the nectar treatment by morph interaction $(F$ $><0.7, P>0.4$ for all; Appendix E). Thrum plants produced fewer seeds per fruit than pin plants $\left(F_{1,72}=\right.$
8.28, $P=0.005$; Appendix E), but floral morph did not affect any other measure of female reproduction, including the total seeds produced per plant $\left(F_{1,72}=\right.$ 0.08, $P>0.7$ ).

In 2004, when high nectar alkaloids were within the natural range, nectar treatment, floral morph, and their interaction had no effect on pollen receipt $\left(F_{1,37}<0.75\right.$, $P>0.4$ for all). However, the number of fruits produced per plant was affected by the interaction between nectar alkaloids and floral morph $\left(F_{1,71}=4.57, P=\right.$ $0.036)$, although there was no significant main effect of either factor $\left(F_{1,71}<0.4, P>0.5\right.$ for both $)$. Highalkaloid nectar reduced fruit production in thrum plants, but had little effect in pin plants (Appendix E). Of plants that produced fruits, there was no effect of nectar treatment, floral morph, or their interactions on the proportion or number of seeds per fruit $\left(F_{1,54}<\right.$ $1.25, P>0.25$ for all; Appendix E).

\section{Direct effect of nectar alkaloids on female plant reproduction}

In hand-pollinated plants in the greenhouse, nectar alkaloids had no direct effect on flower production ( $\mathrm{df}$ $=23, t=-1.26, P=0.22)$, fruit production $(\mathrm{df}=$ $23, t=-0.26, P=0.79)$, proportion of fruit set $(\mathrm{df}$ $=23, t=0.8, P=0.43)$, seeds per fruit $(\mathrm{df}=22, t$ $=0.03, P=0.98)$, or proportion of seed set $(\mathrm{df}=22$, $t=-0.67, P=0.51)$. Because this experiment used artificially high differences in nectar alkaloid levels and found no effects, we did not repeat the experiment using the natural range of alkaloid levels.

\section{DISCUSSION}

\section{Nectar alkaloid impacts on male and female reproduction}

The observation that secondary compounds are common in floral nectar has led to the formulation of several adaptive hypotheses (reviewed in Adler 2000). Such hypotheses assume that nectar compounds benefit plants and that nectar traits are heritable and therefore can evolve in response to selection. Although only a handful of studies have examined the heritability of nectar traits, most have found substantial heritable variation (reviewed in Mitchell 2004). However, the plant fitness consequences of secondary compounds in nectar have remained largely unexplored. A limited number of studies have tested the effect of secondary compounds in nectar on insect or bird behavior in the lab or in artificial feeders (e.g., Stephenson 1982, Detzel and Wink 1993, Hagler and Buchmann 1993, TadmorMelamed et al. 2004). Through manipulative studies of secondary compounds in the nectar of Gelsemium, we found little evidence for benefits of nectar alkaloids on plant reproduction. Nectar alkaloids typically affected the quality, but not quantity, of floral visits, generally decreasing the proportion of flowers probed and time spent per flower for most pollinators and the nectar 
robber. This suggests that any deterrent properties of nectar alkaloids do not act until the visitor has tasted the reward. High levels of nectar alkaloids decreased an estimate of male plant reproduction from one-third to one-half, with little effect on estimates of female plant reproduction. Taken together, our findings suggest that secondary compounds in nectar provide more costs than benefits to plant reproductive success.

Nectar alkaloids had no consistent effect on our measures of female reproduction, but reduced the estimates of male reproduction. These results underscore the importance of considering the effects of phenotypic traits on both male and female fitness components. Traits or interactions that influence pollination may have stronger effects on male than female plant function (Young and Stanton 1990, Stanton et al. 1991, Lehtila and Strauss 1999), although this is not always the case (Gronemeyer et al. 1997, Irwin and Brody 2000). Highalkaloid nectar reduced both the proportion of flowers probed and the time spent per flower by some pollinators. Reducing per-flower visitation and time per flower by legitimate floral visitors can reduce components of male reproduction, including pollen removal and donation, and seeds sired (e.g., Mitchell and Waser 1992, Hodges 1995). More mechanistic studies linking changes in floral visitor behavior to male plant reproduction in Gelsemium are needed to understand how visitor behavior translates into reproduction (as in Stanton et al. 1991). Moreover, we only included one component of male reproduction, pollen (dye) donation, which typically is strongly influenced by floral visitor behavior. Once pollen has reached the stigma, a suite of post-pollination processes, such as pollen competition, incompatibility among pollen and maternal genotypes, and nonrandom fruit and seed abortion, can influence ultimate male reproductive success (e.g., Marshall 1988, Marshall and Ellstrand 1988). Given the strong negative effects of nectar secondary compounds on pollen donation, assessing the link between pollen transfer and realized male reproduction in plants with high vs. low alkaloids is clearly warranted.

\section{What drives the lack of consistent effects on female plant reproduction?}

The lack of consistent effects of high nectar alkaloids on female plant reproduction could be driven by a number of mechanisms. One possibility is that none of the plant-insect interactions considered has substantial effects on female reproduction at our sites. In the greenhouse, we found that nectar alkaloids had no direct effects on fruit or seed production in the absence of pollinators, suggesting that any effects of nectar alkaloids on plant reproduction in the field would be driven indirectly through changes in floral interactions. Given the high levels of floral visits at our experimental sites, plants may not have been pollen limited for fruit or seed production, and thus, changes in floral visitor behavior may not affect reproduction. Additionally, changes in the extent of pollen limitation across years may explain the lack of effect of nectar alkaloids on fruit and seed production in 2002, when pollinator visitation was high, but the reduction in fruit set in one floral morph in 2004, when pollinator visitation was low due to cold weather. If nectar robbing also has little effect on plant reproduction (as in Maloof and Inouye 2000, Irwin et al. 2001), then the effects of nectar alkaloids on pollinator and nectar robber behavior may not translate into differences in fruit or seed production.

Alternatively, the costs and benefits of nectar alkaloids may balance, resulting in little net effect. The effects of nectar alkaloids on floral visitor behavior could cause many non-mutually exclusive costs and benefits. First, if pollinator visits are beneficial and nectar robbing is costly, the costs of reduced pollination in plants with high-alkaloid nectar may outweigh benefits of reduced robbing. The effect of artificially high nectar alkaloids on nectar robbers in 2002 was relatively weak compared to the deterrence of most pollinators (Fig. 1). Even when nectar alkaloids were within the natural range of variation in 2004, high nectar alkaloids significantly reduced the proportion of flowers probed by Osmia, one of the most common and efficient pollinators, while Xylocopa robbed only marginally fewer flowers. Thus, although nectar alkaloids do confer resistance to nectar robbers, the corresponding cost of deterring pollinators may outweigh any benefits. In addition, when nectar alkaloids were manipulated at natural concentrations, they had opposite effects on Osmia and Apis pollinators. These changes might be costly because Osmia transfers three times more pollen per visit than does Apis (L. S. Adler and R. E. Irwin, unpublishd manuscript), or they might balance and result in little net effect on plant reproduction.

Changes in pollinator behavior could have more subtle costs and benefits on plant reproduction by influencing geitonogamy or outcrossing distance. Some pollinators visited more available flowers on plants with low-alkaloid nectar compared to plants with high-alkaloid nectar. Thus, plants with low levels of alkaloids may benefit from increased per-flower visitation but also suffer from increased geitonogamy (de Jong et al. 1993), which could clog stigmas, reduce the delivery of outcross pollen, and decrease fruit or seed production in self-incompatible Gelsemium. The benefits of increased per-flower visitation may balance out the costs of increased geitonogamy in plants with low nectar alkaloids. We also found that in 2002, when we used artificially high levels of alkaloids, Bombus and Habropoda flew greater distances after visiting a plant with high vs. low alkaloids. Traits that cause a pollinator to move farther before visiting another plant could increase pollen flow and outcrossing distances (Maloof 2001), potentially increasing seed quantity or quality (Waser and Price 1989) and outweighing pos- 
sible costs of reduced pollinator preference. However, benefits of increased outcrossing distance will only occur when plant populations exhibit spatial genetic structure and when there are direct links between pollinator movement, pollen flow, and realized gene flow (reviewed in Irwin 2003). These assumptions have yet to be tested in Gelsemium.

\section{Interspecific variation in bee behavior}

In addition to the benefit of deterring nectar robbers, secondary compounds in nectar have also been hypothesized to benefit plants by deterring generalist or inconsistent pollinators (Baker and Baker 1975, Rhoades and Bergdahl 1981). We found little evidence to support this hypothesis. Most of the floral visitors in this study were generalists to some extent, suggesting that the nectar alkaloids naturally present in Gelsemium have not encouraged highly specialized interactions. Some of the most generalized floral visitors were the least deterred by high nectar alkaloids. For example, high nectar alkaloids within the natural range increased the proportion of flowers probed and time spent per flower by Apis mellifera, one of the most generalist pollinators (Fig. 1). This effect represents the only instance of a positive effect of nectar alkaloids on floral visitor behavior in this study. The reason for this result is unclear, especially given that Gelsemium nectar causes abnormal development of young worker honey bees of an Italian strain (Burnside and Vansell 1936). Additionally, Xylocopa, which robs a wide range of flowering plant species and is the only flower visitor that foraged only for nectar, was relatively weakly deterred by nectar alkaloids even at unnaturally high concentrations. Regardless of the mechanisms that affect bee responses to nectar alkaloids, our results provide little support for the hypothesis that nectar secondary compounds deter generalist floral visitors.

\section{Differences between floral morphs}

Heterostyly occurs in $\sim 25$ angiosperm families and is typically viewed as a mechanism to encourage outcrossing (reviewed in Barrett 1990). In the case of Gelsemium, each morph can only set seed when pollinated by the other morph (Ornduff 1970). If pollen flow is asymmetrical between the morphs due to floral visitor behavior or other factors, then differential reproductive success could occur. One intriguing result of our study was the effect of floral morph and, in some cases, the interaction between floral morph and nectar treatment, on pollinator behavior and female plant reproduction. For example, Xylocopa spent nearly $20 \%$ less time robbing pin compared to thrum flowers in 2002, and responded differently to nectar treatments between floral morphs in 2004. Also in 2002, Osmia probed more available flowers in the high-alkaloid than the lowalkaloid treatment in pin flowers, but exhibited the opposite response to thrum flowers. The mechanistic reasons for these visitor-specific responses to floral morphs may be linked to foraging behaviors (i.e., foraging for nectar or pollen) or to correlations between morph and other floral or nectar traits (e.g., Leege and Wolfe 2002). Moreover, in 2004, high-alkaloid nectar reduced fruit production in thrum plants, but had little effect in pin plants (Appendix E). This result was surprising, because high-alkaloid nectar reduced robbing in thrum but not pin flowers. We would have predicted that high-alkaloid nectar would increase, rather than decrease, reproduction in thrum plants, if robbing had a negative effect on plant reproduction. Moreover, $\mathrm{Ha}$ bropoda spent nearly twice as much time in pin flowers with low-alkaloid nectar than any other treatment combination, which suggests a cost of high-alkaloid nectar in pin but not thrum plants. Thus, the costs of highalkaloid nectar in thrum plants did not correspond with insect behavioral responses to alkaloids in the different morphs. More work in natural populations is required to tease apart the relationships among morph type, nectar secondary compounds, and male and female plant fitness.

\section{Conclusion}

Secondary compounds in nectar are widespread (Baker 1977, Adler 2000); however, the relationship between these compounds and plant fitness has remained poorly understood. Here we provide experimental evidence that secondary compounds in the nectar of Gelsemium generally decreased the proportion of flowers probed and time spent per flower for most floral visitors. Nectar alkaloids decreased an estimate of male plant reproduction and had little consistent effect on estimates of female reproduction. If nectar secondary compounds provide more fitness costs than benefits in Gelsemium, what maintains variation in this trait? If nectar secondary compounds are heritable, variation could be maintained through a number of mechanisms, including spatiotemporal variation in selection driven by variation in the abundance of pollinators vs. nectar robbers (Thompson and Cunningham 2002). Alternatively, the presence of alkaloids in nectar may be a pleiotropic consequence of their production in other plant tissues and transport through the phloem. To address the possibility that links between defense levels in different tissues constrain the ability of plants to evolve optimal solutions in the context of interactions with multiple antagonists and mutualists, studies of the genetic and environmental factors that determine defense expression across multiple plant tissues, including roots, leaves, stems, flowers, nectar, and fruits, will provide the most constructive ecological and evolutionary insights.

\section{ACKNOWLEDGMENTS}

We thank J. Affolter and the Botanical Gardens of the University of Georgia (UGA) for use of the field site; A. Tull and M. Smith for greenhouse maintenance and the use of greenhouse field space; M. Wink for nectar gelsemine analysis; J. Neff for bee identification; J. Barron, L. Burkle, G. 
Crutsinger, B. DeGasperis, G. Gisler, A. Lentz, A. H. Norden, H. Prendeville, J. Tian, and R. Wallace for hard work in the field and greenhouse; and A. Agrawal, T.-L. Ashman, A. McCall, P. Warren, and two anonymous reviewers for comments on the manuscript. This research was funded by the Virginia Tech Dept. of Biology (L. S. Adler), UGA Institute of Ecology (R. E. Irwin), and NSF DEB-0211480 (L. S. Adler and R. E. Irwin).

\section{Literature Cited}

Adler, L. S. 2000. The ecological significance of toxic nectar. Oikos 91:409-420.

Adler, L. S., and J. L. Bronstein. 2004. Attracting antagonists: does floral nectar increase leaf herbivory? Ecology 85: 1519-1526.

Baker, H. G. 1977. Non-sugar chemical constituents of nectar. Apidologie 8:349-356.

Baker, H. G., and I. Baker. 1975. Studies of nectar-constitution and pollinator-plant coevolution. Pages 100-140 in L. E. Gilbert and P. H. Raven, editors. Coevolution of plants and animals. University of Texas Press, Austin, Texas, USA.

Barrett, S. C. H. 1990. The evolution and adaptive significance of heterostyly. Trends in Ecology and Evolution 5 : 144-148.

Burnside, C. E., and G. H. Vansell. 1936. Plant poisoning of bees. E-398, USDA, Bureau of Entomology and Plant Quarantine, Washington, D.C., USA.

Chapin, F. S., P. M. Vitousek, and K. Vancleve. 1986. The nature of nutrient limitation in plant communities. American Naturalist 127:48-58.

de Jong, T. J., N. M. Waser, and P. G. L. Klinkhamer. 1993. Geitonogamy: the neglected side of selfing. Trends in Ecology and Evolution 8:321-325.

Detzel, A., and M. Wink. 1993. Attraction, deterrence or intoxication of bees (Apis mellifera) by plant allelochemicals. Chemoecology 4:8-18.

Dudash, M. R. 1991. Plant size effects on female and male function in hermaphroditic Sabatia angularis (Gentianaceae). Ecology 72:1004-1012.

Eckert, J. E. 1946. Injury to bees by poisoning. Pages 570582 in R. A. Grout, editor. The hive and the honey bee. Dadant and Sons, Hamilton, Illinois, USA.

Ehrlen, J., and O. Eriksson. 1993. Toxicity in fleshy fruits: a non-adaptive trait? Oikos 66:107-113.

Galen, C., and J. Cuba. 2001. Down the tube: pollinators, predators, and the evolution of flower shape in the alpine skypilot, Polemonium viscosum. Evolution 55:1963-1971.

Gronemeyer, P. A., B. J. Dilger, J. L. Bouzat, and K. N. Paige. 1997. The effects of herbivory on paternal fitness in scarlet gilia: better moms also make better pops. American Naturalist 150:592-602.

Hagler, J. R., and S. L. Buchmann. 1993. Honey bee (Hymenoptera: Apidae) foraging responses to phenolic-rich nectars. Journal of the Kansas Entomological Society 66 : 223-230.

Hardin, J. W., and J. M. Arena. 1969. Human poisoning from native and cultivated plants. Duke University Press, Durham, North Carolina, USA.

Heinrich, B. 1983. Insect foraging energetics. Pages 187214 in C. E. Jones and R. F. Little, editors. Handbook of experimental pollination biology. Van Nostrand Reinhold, New York, New York, USA.

Hodges, S. A. 1995. The influence of nectar production on hawkmoth behavior, self pollination, and seed production in Mirabilis multiflora (Nyctaginaceae). American Journal of Botany 82:197-204.

Irwin, R. E. 2003. Impact of nectar robbing on estimates of pollen flow: conceptual predictions and empirical outcomes. Ecology 84:485-495.
Irwin, R. E., and A. K. Brody. 1999. Nectar-robbing bumble bees reduce the fitness of Ipomopsis aggregata (Polemoniaceae). Ecology 80:1703-1712.

Irwin, R. E., and A. K. Brody. 2000. Consequences of nectar robbing for realized male function in a hummingbird-pollinated plant. Ecology 81:2637-2643.

Irwin, R. E., A. K. Brody, and N. M. Waser. 2001. The impact of floral larceny on individuals, populations, and communities. Oecologia 129:161-168.

Kearns, C. A., and D. W. Inouye. 1993. Techniques for pollination biologists. University Press of Colorado, Niwot, Colorado, USA.

Kingsbury, J. M. 1964. Poisonous plants of the United States and Canada. Prentice-Hall, Englewood Cliffs, New Jersey, USA.

Leege, L. M., and L. M. Wolfe. 2002. Do floral herbivores respond to variation in flower characteristics in Gelsemium sempervirens (Loganiaceae), a distylous vine? American Journal of Botany 89:1270-1274.

Lehtila, K., and S. Y. Strauss. 1999. Effects of foliar herbivory on male and female reproductive traits of wild radish, Raphanus raphanistrum. Ecology 80:116-124.

Maloof, J. E. 2001. The effects of a bumble bee nectar robber on plant reproductive success and pollinator behavior. American Journal of Botany 88:1960-1965.

Maloof, J. E., and D. W. Inouye. 2000. Are nectar robbers cheaters or mutualists? Ecology 81:2651-2661.

Marshall, D. L. 1988. Postpollination effects on seed paternity: mechanisms in addition to microgametophyte competition operate in wild radish. Evolution 42:1256-1266.

Marshall, D. L., and N. C. Ellstrand. 1988. Effective mate choice in wild radish: evidence for selective seed abortion and its mechanism. American Naturalist 131:739-756.

Mitchell, R. J. 2004. Heritability of nectar traits: why do we know so little? Ecology 85:1527-1533.

Mitchell, R. J., and N. M. Waser. 1992. Adaptive significance of Ipomopsis aggregata nectar production: pollination success of single flowers. Ecology 73:633-638.

Ornduff, R. 1970. Systematics and breeding system of Gelsemium (Loganiaceae). Journal of the Arnold Arboretum 51:1-17.

Ornduff, R. 1979. Features of pollen flow in Gelsemium sempervirens (Loganiaceae). Journal of the Arnold Arboretum 60:377-381.

Power, M. E., W. E. Dietrich, and K. O. Sullivan. 1998. Experimentation, observation, and inference in river and watershed investigations. Pages 113-132 in W. J. J. Resetarits and J. Bernardo, editors. Experimental ecology: issues and perspectives. Oxford University Press, New York, New York, USA.

Rhoades, D. F., and J. C. Bergdahl. 1981. Adaptive significance of toxic nectar. American Naturalist 117:798-803.

SAS Institute. 1999. SAS Version 8. SAS Institute, Cary, North Carolina, USA.

Simms, E. L., and M. A. Bucher. 1996. Pleiotropic effect of flower color intensity on resistance to herbivory in Ipomoea purpurea. Evolution 50:957-963.

Stanton, M., H. J. Young, N. C. Ellstrand, and J. M. Clegg. 1991. Consequences of floral variation for male and female reproduction in experimental populations of wild radish, Raphanus sativus L. Evolution 45:268-280.

Stephenson, A. G. 1982. The role of the extrafloral nectaries of Catalpa speciosa in limiting herbivory and increasing fruit production. Ecology 63:663-669.

Strauss, S. Y., and K. P. Lehtila. 1997. Patterns of compensation from foliar herbivory in male and female fitness characters or wild radish, Raphanus raphanistrum. Bulletin of the Ecological Society of America 78:192.

Strauss, S. Y., D. H. Siemens, M. B. Decher, and T. MitchellOlds. 1999. Ecological costs of plant resistance to herbi- 
vores in the currency of pollination. Evolution 53:11051113.

Tadmor-Melamed, H., S. Markman, A. Arieli, M. Distl, M. Wink, and I. Izhaki. 2004. Limited ability of Palestine sunbirds (Nectarinia osea) to cope with pyridine alkaloids in nectar of tree tobacco, Nicotiana glauca. Functional Ecology 18:844-850.

Thompson, J. N., and B. M. Cunningham. 2002. Geographic structure and dynamics of coevolutionary selection. Nature 417:735-738.
Waser, N. M., and M. V. Price. 1982. A comparison of pollen and fluorescent dye carry-over by natural pollinators of Ipomopsis aggregata (Polemoniaceae). Ecology 63:11681172.

Waser, N. M., and M. V. Price. 1989. Optimal outcrossing in Ipomopsis aggregata: seed set and offspring fitness. Evolution 43:1097-1109.

Young, H. J., and M. L. Stanton. 1990. Influences of floral variation on pollen removal and seed production in wild radish. Ecology 71:536-547.

\section{APPENDIX A}

Methods of HPLC-MS analysis of Gelsemium nectar samples are available in ESA's Electronic Data Archive: Ecological Archives E086-161-A1.

\section{APPENDIX B}

A table showing the effect of nectar treatment (high vs. low gelsemine), floral morph (pin vs. thrum), and their interaction on components of bee preference in 2002 is available in ESA's Electronic Data Archive: Ecological Archives E086-161-A2.

\section{APPENDIX C}

A table showing the effect of nectar treatment (high vs. low alkaloid), floral morph (pin vs. thrum), and their interaction on components of bee preference in 2004 is available in ESA's Electronic Data Archive: Ecological Archives E086-161-A3.

\section{APPENDIX D}

A table showing the repeated-measures analysis of dye donation per flower dyed in 2002 is available in ESA's Electronic Data Archive: Ecological Archives E086-161-A4.

\section{APPENDIX E}

A table showing the means \pm standard error for measures of female reproduction in 2002 and 2004, broken down by floral morph and nectar treatment, is available in ESA's Electronic Data Archive: Ecological Archives E086-161-A5. 